\title{
Autoconhecimento como estratégia formativa do professor
}

\author{
Self-knowledge as a teacher's training strategy
}

\section{El autoconocimiento como estrategia de formación del profesor}

\author{
MARCIA GOUVÊA LOUSADA (iDa
}

Maribel Oliveira Barreto

\section{Resumo}

Diante da modificação ocorrida na Base Nacional Comum Curricular (BNCC), pela qual espera-se que o professor desenvolva competências em seus estudantes, as quais englobem uma formação humana e ética, além da formação técnica e com especial relevância para o autoconhecimento e autocuidado, mostra-se necessário compreender como os autores da área realizam tal desenvolvimento. Para tanto foram analisados 22 resumos de artigos, dissertações e teses publicadas entre 2015 e 2020 nas plataformas do Educ@ e da Biblioteca Digital Brasileira de Teses e Dissertações (BDTD) a fim de conhecer as técnicas empregadas na promoção de tal capacidade e/ou habilidade. Como resultado encontraram-se tentativas de agregar a compreensão intrapsíquica na educação, sendo utilizadas diversas estratégias que vão desde a simples reflexão sobre si e a conscientização das escolhas realizadas e a realizar até a combinação de técnicas e teorias da Psicologia, muitas vezes já utilizadas no mundo corporativo. Outra tendência manifestada nesta investigação foi a inclusão de uma visão mais abrangente de Ser Humano, a necessidade e importância de uma visão holística, de um Ser Humano Integral que possibilite abarcar um trabalho que atue com as dimensões físico/corporal, afetivo/emocional, cognitivo/mental, social e espiritual/transcendente.

Palavras-chave: Autoconhecimento. Formação de Professores. Espiritualidade.

\begin{abstract}
In view of the modification that occurred in the National Common Curricular Base (BNCC), according to which the teacher has to develop skills in his students, which
\end{abstract}

\footnotetext{
a Pontifícia Universidade Católica de São Paulo (PUC-SP), São Paulo, SP, Brasil. Doutora em Psicologia da Educação, e-mail: marciaglousada@gmail.com

${ }^{b}$ Instituto Superior de Educação Ocidente, Salvador, BA, Brasil. Doutora em Educação, e-mail: maribelbarreto1@gmail.com
} 
include human and ethical education, in addition to technical education and with special relevance for self-knowledge and self-care, it is necessary to understand how the authors of the area carry out such development. To achieve this goal, 22 abstracts of articles, dissertations and theses published between 2015 and 2020 on the platforms of Educ@ and the Brazilian Digital Library of Theses and Dissertations (BDTD) were analyzed in order to learn the techniques employed in promoting such capacity and/or skill. As a result, attempts were found to aggregate intrapsychic understanding in education, using several strategies ranging from simple reflection on oneself and awareness of the choices made and that will be made, to the combination of techniques and theories of Psychology, which were many times already used in the corporate world. Another trend manifested in this investigation was the inclusion of a more comprehensive view of the Human Being, the need and importance of a holistic view, of an Integral Human Being that makes it possible to encompass a work that includes several dimensions: physical/body, affective/emotional, cognitive/mental, social and spiritual/transcendent.

Keywords: Self-knowledge. Teacher training. Spirituality.

\section{Resumen}

Ante la modificación que se produjo en la Base Curricular Común Nacional (BNCC), para lo cual se espera que el docente desarrolle habilidades en sus alumnos, que incluyen la formación humana y ética, además de la formación técnica y con especial relevancia para el autoconocimiento y el autocuidado, es necesario comprender cómo los autores del área llevan a cabo dicho desarrollo. Para ello, se analizaron 22 resúmenes de artículos, disertaciones y tesis publicados entre 2015 y 2020 en las plataformas de Educ@ y la Biblioteca Digital Brasileña de Tesis y Disertaciones (BDTD) con el fin de conocer las técnicas empleadas en la promoción de dicha capacidad y / o habilidad. Como resultado, se encontraron intentos de agregar la comprensión intrapsíquica en la educación, utilizando varias estrategias que van desde la simple reflexión sobre uno mismo y la conciencia de las decisiones tomadas y por tomar, hasta la combinación de técnicas y teorías de la Psicología, a menudo utilizadas en el mundo empresarial. Otra tendencia manifestada en esta investigación fue la inclusión de una visión más integral del Ser Humano, la necesidad e importancia de una visión holística, de un Ser Humano Integral que posibilite acoger un trabajo que incluye las dimensiones física/corporal, afectiva/emocional, cognitiva/mental, social y espiritual/trascendente.

Palabras clave: Conocimiento de sí mismo. Formación de profesores. Espiritualidad.

\section{Introdução}

De acordo com a Base Nacional Comum Curricular (BNCC), ao longo das três etapas da educação básica, será necessário desenvolver nos estudantes dez competências gerais que materializam os direitos de aprendizagem e de desenvolvimento no âmbito pedagógico. Entre outras proposições, almeja-se que o 
educador ultrapasse o ensino tradicional e desenvolva em seus estudantes, além da formação técnica, também a formação humana e ética. Para tanto, destaca-se a importância de o professor cuidar de sua saúde física e emocional, compreender-se enquanto Ser Humano, ser capaz de reconhecer emoções, tanto suas como dos outros, tendo capacidade de lidar com elas (BRASIL, 2017).

Em fevereiro de 2020, o Ministério da Educação divulgou novas diretrizes para a formação de professores, incrementando, na proposição anteriormente descrita, a necessidade de desenvolver o autoconhecimento e autocuidado nos estudantes (BRASIL, 2020).

Alguns autores apostam que, para ocorrer tal mudança, será necessário que o professor participe, primeiro, de um processo de mudança e transformação dele mesmo, pois apenas exercendo o autoconhecimento e o autocuidado será possível ensinar ao Outro (LOUSADA, 2017). Só assim, portanto, estará habilitado para atender as exigências pedagógicas preconizadas nas novas diretrizes para a formação do professor.

Diante de tal orientação, torna-se fundamental pesquisar a respeito do tema na literatura da área, a fim de compilar e delinear a pedagogia utilizada/necessária para que se promova no Outro, no caso o aluno, o desenvolvimento de conhecimento e cuidado em relação a si próprio.

De acordo com Lousada (2017), entrar em contato com a espiritualidade implica um movimento em direção a si mesmo, um olhar para si e seu potencial, isto é, a confluência de uma força motora e transformadora que provocaria processos de crescimento pessoal, impulsionando o sujeito a novas atitudes e experiências, com a possibilidade de busca de autonomia e realização do potencial humano. Aponta, também, o olhar para o transcendente, que seria a busca de sentido e propósito de vida, de conexão a uma força em direção a uma totalidade maior, encontrada na Natureza, na arte e no pensamento racional. Por fim, o olhar para o Outro, que implica a busca de relações humanas satisfatórias, o recebimento e a doação de energia para o outro, a demanda por um significado que vá além da identidade individual ou do grupo, assim como o respeito à singularidade alheia, visto que respeita a si mesmo. Dessa forma, o contato com a dimensão espiritual auxiliaria no desenvolvimento de uma visão integral de si mesmo, em compreender e saber lidar com suas emoções e 
as do Outro, portanto, em uma visão mais humana e ética, culminando em autoconhecimento e autocuidado de si e do Outro.

Necessário é indicar que Lousada (2017) realizou uma revisão de literatura tipo estado do conhecimento acerca do tema Espiritualidade em três áreas do saber (Psicologia, Saúde e Educação) e o "movimento em direção a si", descrito anteriormente, foi salientado nas três áreas, porém apenas na área da Educação evidenciou-se o termo autoconhecimento.

Destacando os registros encontrados na obra a respeito do termo, primeiramente cumpre apontar que os autores pesquisados acreditam na necessidade de um professor mais completo e mais consciente de si, para que tenha a capacidade de despertar a necessidade de autoconhecimento de seus alunos, portanto de formar pessoas mais próximas de sua subjetividade e de seus valores (LOUSADA, 2017), o que vai ao encontro da BNCC (BRASIL, 2017) e das Novas Diretrizes para a Formação de Professor (BRASIL, 2020).

Esses autores compreendem que o autoconhecimento é condição primária para acontecer um ser Humano Integral, em que o corpo, os sentimentos, a cognição, a intuição, a imaginação e a espiritualidade, ou seja, o sentir, o pensar e o agir possam articular e manifestar-se com coerência e com respeito a si e ao Outro (LOUSADA, 2017).

Para que o desenvolvimento enquanto Ser Humano ocorra, torna-se necessário um investimento em si mesmo, uma busca pelo autocrescimento e aprimoramento de si, de sua autoconfiança e autoestima, para que aconteça o respeito a si e ao Outro (GODOY, 2011).

Como a pesquisa de Lousada compilou informações entre os anos de 2010 e 2015, este artigo se propõe a analisar publicações apenas na área da Educação, entre 2015 a 2020, a fim de compreender se o autoconhecimento, compreendido no estudo sobre a Espiritualidade, está sendo utilizado na formação de professores e, nesse caso, quais são as técnicas empregadas a fim de desenvolver tal capacidade nos educadores.

Iniciou-se por uma pesquisa nas plataformas de pesquisa Educ@, Scholar Google, Periódicos da Capes e Biblioteca Digital Brasileira de Teses e Dissertações (BDTD) utilizando as palavras chaves "Autoconhecimento", "Formação", "Formação de Professor" e "Formação docente". 
O Educ@ é um indexador que possibilita o acesso a várias coleções de periódicos científicos na área da educação. Este indexador congrega 56 periódicos com publicações, sendo 52 periódicos correntes e 4 não-correntes. A coleção "Caderno de Pesquisa" é um dos periódicos com data mais antiga, 1971, e continua corrente, isto é, permanece sendo publicado até os dias de hoje. Desta forma podemos compreender que este indexador compila publicações da área de Educação ao longo de 49 anos. A busca no universo de textos publicados apontou a existência de onze (11) artigos que possuem os termos "formação" e "autoconhecimento" como palavras-chave e apenas uma publicação que possuía "formação docente" e “autoconhecimento" como palavras-chave. Já os termos “formação de professor" e "autoconhecimento" não apresentaram nenhuma publicação.

O Scholar Google ou Google Acadêmico é uma base de dados que reúne artigos científicos, teses, livros e jornais de universidades de todo o universo acadêmico. Utilizou-se a ferramenta pesquisa avançada, definindo-se pela busca de artigos entre os anos de 2015 a 2020. Entre estes anos foram encontrados 16.300 trabalhos com as palavras-chave "formação" e "autoconhecimento"; 15.000 com as palavras-chave "formação de professor" e "autoconhecimento" e 15.900 textos foram encontrados ao se utilizar as palavras-chave "formação docente" e "autoconhecimento". Acrescentando o filtro "Educação", foram encontrados 1.860 textos com os filtros "formação" e "autoconhecimento"; 1.600 com as palavras-chave "formação de professor" e "autoconhecimento" e 1.370 com as palavras-chave "formação docente" e "autoconhecimento".

O Portal de Periódicos da Capes é uma biblioteca virtual que congrega o melhor da produção científica internacional. Em seu acervo, constam mais de 45 mil periódicos com texto completo, 130 bases referenciais, 12 bases dedicadas exclusivamente a patentes, além de livros, enciclopédias e obras de referência, normas técnicas, estatísticas e conteúdo audiovisual (UNIVERDIDADE..., 2019) Neste Portal, além das palavras chaves colocadas, utilizaram-se os seguintes filtros: últimos 5 anos; artigos; qualquer idioma, que apontou a existência de 189 artigos que possuem os termos "autoconhecimento" e "formação"; 69 artigos quando a busca se deu com as palavras "formação de professor" e "autoconhecimento" e 60 artigos com as palavras-chave "formação docente" e "autoconhecimento". 
A Biblioteca Digital Brasileira de Teses e Dissertações (BDTD) integra os sistemas de informação existentes na Instituições de Ensino, congregando teses e dissertações produzidas em território nacional e no exterior, o que confere maior visibilidade para a produção científica nacional. Nesta plataforma utilizaram-se as mesmas palavras-chave, acrescentando os filtros de 2015 a 2020; área de conhecimento Educação e Educação: currículo. Como resultado desta busca obtiveram-se onze (11) trabalhos ao utilizar as palavras-chave "formação" e "autoconhecimento", oito (8) quando as palavras-chave colocadas foram "formação de professor e autoconhecimento" e cinco (5) pesquisas utilizando-se os termos "formação docente" e "autoconhecimento".

Segue quadro ilustrativo com a quantidade de artigos encontrados nas buscas realizadas, de acordo com os critérios anteriormente mencionados.

Quadro 1 - Quantidade de artigos por plataforma

\begin{tabular}{|c|c|c|c|c|}
\hline PALAVRA-CHAVE & $\begin{array}{c}\text { EDUCA - } \\
\text { artigos }\end{array}$ & $\begin{array}{c}\text { Scholar } \\
\text { Google }\end{array}$ & $\begin{array}{c}\text { Periódicos } \\
\text { CAPES }\end{array}$ & BDTD \\
\hline $\begin{array}{c}\text { Formação x } \\
\text { Autoconhecimento }\end{array}$ & 11 & 1.860 & 189 & 11 \\
\hline $\begin{array}{c}\text { Formação de professor } \\
\text { x Autoconhecimento }\end{array}$ & 0 & 1.600 & 69 & 8 \\
\hline $\begin{array}{c}\text { Formação docente x } \\
\text { Autoconhecimento }\end{array}$ & 1 & 1.370 & 60 & 5 \\
\hline
\end{tabular}

Fonte: Dados obtidos nos sites do Educ@, Scholar Google, Capes e BDTD.

Para este artigo serão analisados os resultados encontrados nas bibliotecas digitais do Educ@ e do BDTD, utilizando as palavras-chave "Formação" e "Autoconhecimento", tendo em vista que a utilização das palavras-chave "formação de professor" e "formação docente" apontou um número menor de trabalhos, indicando que estão compilados na categoria mais ampla. O critério de escolha pela análise das duas plataformas deve-se ao fato de serem referências para a área de Educação, deixando para outro momento a análise das outras plataformas. Desta forma analisaram-se vinte e dois (22) artigos. 


\section{Análise do resumo dos artigos, dissertações e teses}

$\mathrm{Na}$ análise dos resumos dos artigos compilados foi possível verificar que, em seis (6) deles, o autor destacou a importância do autoconhecimento, porém não apontou a estratégia para seu desenvolvimento. O destaque para a relevância da autognose apresentada nestes seis artigos versava sobre temáticas diversas como: a formação/currículo do administrador escolar; os professores "readaptados", que seriam os afastados por doença e descontentes com sua nova função; assim como alunos que precisam aprender sobre a própria sexualidade ou para que aprendam a ser eticamente livres e responsáveis; conhecer o real propósito de ser professor e a sugestão de se tratar deste aspecto na formação continuada de professores de educação física.

[...] foi possível construir uma série de aportes teóricos e práticos para o desenvolvimento de um currículo repleto de potencialidades de superação das dicotomias existentes no interior da escola hoje, em especial, a pedagógico/administrativo, porque pautado na Interdisciplinaridade, 0 que the permite abordar de maneira mais adequada a complexidade do contexto escolar, por ser integrado e, consequentemente, integrador. Esse currículo estrutura-se a partir de três bases: vivência interdisciplinar; sólida formação teórica e prática; autoconhecimento (FERNANDES, 2018, p. 10).

[...] A análise deste estudo sugere que a valorização do professor readaptado deva estar atrelada às políticas de formação, valorização da carreira e saúde, com foco em seu autoconhecimento e em seu reconhecimento como profissional da educação (DOMINGUES, 2018, p. 7).

[...] também, se constatou que o trabalho com o tema pode promover 0 autoconhecimento dos alunos, o respeito à diversidade e a seus corpos, amenizando os problemas sociais dentro e fora da escola. Este estudo gerou um produto educacional, cujo objetivo foi construir uma alternativa pedagógica para auxiliar o professor da educação básica a planejar suas aulas sobre Educação Sexual (SANTOS, 2019, p. 8).

[...] Os resultados das análises apontam que é preciso empreender, no âmbito escolar, uma formação humana integral que garanta, ao estudante, a competência para se autoconhecer como sujeito eticamente livre e responsável por suas escolhas, vivenciando seu relacionamento com Deus, consigo mesmo, em interação com as pessoas de seu entorno e o meio ambiente (NOVAIS, 2016, p. 8).

[...] Diante dos marcos legais que validam e legitimam o direito dos professores à política pública de formação continuada, estabelece a importância do autoconhecimento como relevante na formação dos professores, conhecendo-se para conhecer a real finalidade de educar (REIS, 2019, resumo).

O objetivo deste estudo foi investigar o habitus dos professores de Educação Física atuantes no ensino fundamental e médio em escolas da rede pública e particular de ensino do município de Ivaiporã, Paraná, com relação ao seu desenvolvimento 
profissional. [...]. Concluímos pela necessidade de o professor envolver-se em um processo de formação continuada que transcenda o desenvolvimento de competências técnicas, mas que envolva também a criticidade, o autoconhecimento, a autonomia e o compromisso político do professor com a educação (BASEI; BENDRATH, 2016, p. 319).

$\mathrm{Na}$ sequência discorre-se sobre os resumos de artigos que apresentaram estratégias utilizadas para o desenvolvimento do autoconhecimento e que foram agrupados por semelhança.

Em um grupo foram compilados resumos que denotaram estratégias que incluem a trajetória de vida e pessoal como caminho para que os sujeitos olhassem para si. Foram encontradas biografias, histórias de vida, experiências e situações vividas, registros escritos e até a literatura para esta finalidade.

[...] no que tange à trajetória formativa [...]. o uso da abordagem das histórias de vida como metodologia privilegia a coleta de informações contidas na vida pessoal, não se tratando de mera descrição de fatos, mas um esforço de reconstrução da memória, atribuindo novos sentidos. E, por fim, constatar que não é possível falar de educação sem aprofundar questões relativas aos sujeitos desse processo, que a fizeram e pensaram, bem como a realidade educacional que viveram [...] (SOARES; MENEZES; FREIRE, 2016, p. 428).

O presente trabalho teve como objetivo geral analisar como experiências vividas por professores, enquanto alunos, reverberam na sua atuação profissional e na formação docente, na fala dos próprios professores. Os objetivos específicos foram identificar, nos relatos dos professores, situações vividas que marcaram suas vidas de estudantes; verificar como tais situações reverberam nas relações professor-aluno-conhecimento, quando se tornaram professores; problematizar os incidentes críticos presentes nas narrativas dos professores e analisá-los como estratégia formativa. [...]. Constatou-se que a utilização de incidentes críticos para embasar a produção de propostas formativas teve resultados positivos, pois, por meio de relatos de episódios marcantes em suas vidas enquanto alunos, os professores tiveram a oportunidade de ressignificar o vivido sob uma nova ótica e, dessa forma, tanto exercitar o autoconhecimento, quanto entender melhor a relevância de seu papel nas relações interpessoais no processo educativo (CORREA, 2020, p. 8).

[...] percebeu-se que a formação se coloca muitas vezes de forma imposta e com pouca participação dos professores nos seus planejamentos e nas suas temáticas. [...] procurou refletir a respeito de suas bagagens, suas origens e como seus saberes interferem em suas práticas e no seu desenvolvimento profissional. Assim, trabalha-se com a seguinte hipótese: Uma formação continuada que considera as experiências, os interesses e a realidade vivida pelos professores promove reflexão e mudanças nas práticas docentes (SILVEIRA, 2017, p. 6).

[...] as crianças escreveram sobre si mesmas em agendas, diários e cartas [...] o que permite interrogar sobre a centralidade que a escrita de cartas teve na aprendizagem dos códigos de civilidade, no autoconhecimento, na formação moral e na internalização de normas gramaticais (MIGNOT, 2013, p. 237). 
[...]. Dentre as apreciações dos alunos quanto ao seu trabalho com os diários de itinerância destacam-se: registrar, nos diários, o que os afetou em sua trajetória escolar e profissional, proporcionou maior intimidade com o texto lido e discutido, e levou-os a reconhecer seu valor como profissional; além disso, forneceu elementos para autoconhecimento, tanto para o autor como para os que participaram da socialização (ALMEIDA, 2012, p. 250).

[...] A literatura é vista como um direito inalienável de todos os seres humanos, que congrega a possibilidade de viver experiências estéticas, de autoconhecimento e de ampliação dos referenciais do mundo. A sala de leitura é concebida como cronotopo, um tempo-espaço de mediações, de interações, de trocas simbólicas, de vida, de eventos dialógicos, de formação de leitores (SCHEFFER, 2019, p. 9).

Em outro grupo reuniu-se resumos nos quais os autores apresentaram, como estratégia para desenvolver o autoconhecimento, o emprego dos tipos psicológicos, tanto aqueles aplicados no mundo corporativo para o gerenciamento de equipes como os tipos psicológicos de Nietzsche.

Uma estratégia para a produção de equipes e o desenvolvimento de competências do trabalho em equipe é o Myers-Briggs Type Indicator (MBTI), amplamente utilizado nos setores de recursos humanos, de gerenciamento e administração na construção de equipes, com o propósito de autoconhecimento e autodesenvolvimento, desenvolvimento organizacional, treinamento gerencial e desenvolvimento curricular acadêmico e profissional (ROSA et al., 2019, p. 15).

[...] elucidação da especificidade da teoria nietzschiana do autoconhecimento e da sua concepção da singularidade [...] que o leva a conceber o filósofo, o artista e o santo como os tipos singulares por excelência nos quais a natureza justifica os seus esforços e supera a mera necessidade. Essas tipologias revelam as tarefas que a educação deve, ao juízo de Nietzsche, perseguir se não quiser se tornar mero abstracionismo ou mera aderência acrítica ao mundo: jamais condescender aos modismos culturais; não separar pensamento e vida com o que se diz, também, que teoria e prática não estão separadas; incorporar a singularidade como aquilo que a educação promove; e, por fim, eleger a autossuperação como a tarefa mais imperiosa para a constituição do humano no seu sentido mais pleno (WEBER, 2009, p. 251).

Alguns autores apontaram em seus resumos a formação continuada como espaço para o desenvolvimento do autoconhecimento de professores, utilizando como ferramenta técnicas diferenciadas, como a pesquisa, a reflexão, a autoformação, trabalhos em grupo e oficinas de autoconhecimento e pedagógicas.

Assumindo a escola como espaço e tempo de desenvolvimento profissional e pessoal, a formação em contexto propõe a articulação entre momentos de formação e trabalho e insiste na importância da pesquisa como estratégia formativa e situação privilegiada para sistematização dos conhecimentos e saberes construídos no interior da escola. Assim, a pesquisa do professor acena com a possibilidade de promover conhecimento e reflexão de si - autoconhecimento -, do outro, sobre o trabalho, as situações, os acontecimentos e as ideias (CUNHA; PRADO, 2010, p. 101). 
Apresenta construtos teóricos que apontam para as possibilidades de autoformação em busca do autoconhecimento, dos profissionais que constituem a base da formação humana de outros seres humanos. Além disso, o artigo apresenta um modelo de educação continuada considerado eficiente pela abordagem de necessidade de atualização de formação, baseado em oficinas pedagógicas, com trabalho cooperativo entre os pares (ANTUNES; PLASZEWSKI, 2018, p. 30)

O presente artigo aborda elementos importantes a respeito do ser professor, as relações interpessoais estabelecidas no ambiente escolar e a relação com o autoconhecimento, a autoestima, a autoimagem e os processos motivacionais. [...] a formação continuada proporcionada pelas oficinas de autoconhecimento, parecem contribuir significativamente para elevar a motivação e promover o bem-estar do professor (SANTOS; ANTUNES; BERNARDI, 2008, p. 46).

[...] No processo de análise de dados, orientamo-nos pela técnica de análise de conteúdo (BARDIN, 2009) que evidenciou que a prática reflexiva pode, de fato, trazer contribuições para formação docente, promovendo o desenvolvimento profissional na medida em que provoca o questionamento sobre a própria ação de ensinar e desenvolver o autoconhecimento, autoanálise e autoavaliação conduzindo a um processo de revisão de concepções e reconstrução de práticas com vistas à inclusão escolar (DANTAS, 2016, p. 9).

Alguns resumos retratam a adoção de uma perspectiva interdisciplinar para desenvolver o autoconhecimento e autocuidado em alunos e professores da educação infantil, do ensino fundamental e médio, bem como da educação superior, empregando e mesclando técnicas como narrativas de si, vivências simbólicas com base Junguiana, o teatro e a Aprendizagem Baseada em Problemas (ABP) como instrumentos para se adquirir uma formação integral.

Esta pesquisa apresenta como tema o desenvolvimento do autoconhecimento e autocuidado vivenciado simbolicamente na formação dos profissionais da saúde. [...] 0 objetivo principal foi compreender o desenvolvimento do autoconhecimento e autocuidado vivenciado simbolicamente nos cursos de graduação do profissional de saúde, incluindo como sujeitos, o pesquisador e os alunos de graduação da área das Ciências da saúde. A partir da metáfora da flor de lótus, possibilitada pela perspectiva interdisciplinar com aporte da Psicologia Simbólica Junguiana, desvelou-se o caminho teórico e metodológico da pesquisa, denominado jornada simbólica. Assim, a investigação apresentou um enfoque metodológico interdisciplinar, portanto, qualitativo e de cunho participativo. Os instrumentos metodológicos foram: as narrativas das vivências simbólicas significativas para o pesquisador durante o desenvolvimento da tese; as narrativas e questionários advindos de um programa educacional vivenciado simbolicamente com os alunos dos cursos de [...] um mapeamento de percepções de aprendizagem realizado mediante um questionário on-line, via internet, proposto para todos os alunos [...] Como principal resultado obtido, foi revelada uma jornada simbólica, permeada pelo autoconhecimento e autocuidado, como um caminho possível na formação interdisciplinar dos profissionais das Ciências da Saúde (ANDRADE, 2018, p. 9).

Esta pesquisa aborda a importância da arte, principalmente a partir do teatro, e do autoconhecimento na construção de um currículo escolar, bem como no processo de formação de professores da Educação Infantil, Ensino Fundamental e Médio, possibilitando servir como orientadores de pesquisa e desenvolvimento de todos os 
conteúdos pertinentes a esses segmentos do processo educativo, demonstrando como essas referências podem orientar e subsidiar todos os conteúdos propostos pela Base Nacional Comum Curricular, principalmente quando propostos a partir de Projetos Interdisciplinares, $[\ldots]$ a intenção de possibilitar ao educando, independente da sua idade, uma aprendizagem efetiva, significativa e prazerosa, integrando os aspectos cognitivo, afetivo e motor, resultando em uma educação integral. Para essa investigação, utilizamos como ponto de partida pensadores da educação, recentes estudos que apontam a Aprendizagem Baseada em Problemas - ABP como uma possibilidade de uma aprendizagem significativa, onde o estudante é coautor do seu processo de aquisição de conhecimento e as referências do trabalho interdisciplinar na perspectiva principal da Profa. Dra. Ivani Fazenda (CORREA, 2018, p. 7).

Outro resumo apresentou a utilização de um conjunto de técnicas para desenvolvimento do autoconhecimento em estudantes do curso de Medicina: a metodologia ativa, reflexão crítica, valorização da autonomia, ressignificação e a Team-Based Learning (TBL) ou Aprendizagem Baseada em Equipes.

O curso de Medicina da Universidade Federal do Pampa desenvolve-se sob pilares transformadores e vanguardistas da metodologia ativa. O curso transcende as práticas e educação biomedicalizadoras tradicionais por meio do reconhecimento dos aspectos humanos e sociais da medicina, em busca de uma formação centrada na visão holística do cuidado, [...] a necessidade de valorizar a autonomia do estudante, por meio de atividades que promovam a reflexão crítica e a aplicabilidade em situações reais dos temas propostos pelos docentes, valorizando ainda a articulação em grupo para diálogo, construção de ideias e resolução de problemas. A apropriação e aplicação de metodologias ativas em ambientes de promoção de saúde contribuem, portanto, para esse ideal de formação. [...]. A atividade foi proposta com base teórica centrada no Aprendizado Baseado em Equipes (Team-Based Learning - TBL), destacando o autoconhecimento, prevenção contra infecções sexualmente transmissíveis, empoderamento no quesito de direitos sexuais e reprodutivos e o consentimento sexual. Foi realizada uma análise dialética das discussões com o propósito de avaliar as atividades realizadas, (re)significar as vivências e compilar as expectativas e impressões acerca da experiência (SANTOS et al., 2019, p. 193).

Pereira e Lima (2013), por sua vez, utilizaram a bioexpressão como estratégia

para desenvolver o autoconhecimento de alunos do curso de Pedagogia.

[...] analisar a Bioexpressão como possibilidade de formação integral dos graduandos do Curso de Pedagogia [...]. A Bioexpressão é um conjunto de conhecimentos teóricovivenciais que visa à compreensão de si e das dificuldades de expressão própria que dificultam a vida, o exercício profissional e as interrelações, considerando o desenvolvimento do ser em sua integralidade, o que abarca as dimensões cognitiva, afetiva, corporal, social e espiritual. O trabalho tem sua base nas teorias de Wilhelm Reich e seus continuadores - Alexander Lowen, Stanley Keleman e David Boadella. As atividades bioexpressivas se mostram como possibilidades de estimular o autoconhecimento do profissional em formação, seu olhar para o outro e seu entorno, gerando reflexões e propostas de novas formas de atuação (PEREIRA; LIMA, 2013, p. 189). 


\section{Considerações finais}

Esta breve pesquisa mostra que existe uma busca por métodos que agreguem a compreensão intrapessoal na Educação e que vários ensaios estão sendo realizados.

Encontraram-se ensaios que apontam estratégias que vão desde a simples reflexão sobre si, suas atitudes, escolhas em geral e escolhas sobre as pesquisas que realizam até abordagens mais complexas, que conjuminam técnicas diferenciadas como a utilização de tipos psicológicos e conceitos/teorias da área da Psicologia, já utilizadas no mundo corporativo, aplicadas na educação/formação de profissionais. A reflexão foi a estratégia que mais se apresentou, associada a atividades/ações que auxiliassem o olhar para si, inclusive voltando-se para a singularidade pessoal como forma de diferenciação e de retomar a si mesmo.

Entre os trabalhos apresentados, dois resumos referem-se à dimensão espiritual, sendo um com conotação da religiosidade e outro com a acepção da espiritualidade ${ }^{12}$. Porém já é sabido que promover o autoconhecimento através da espiritualidade agrega a possibilidade de trabalhar, além da compreensão de si mesmo, o seu próprio potencial, isto é, o empoderamento e a resiliência necessários para uma autonomia/autoria coerente. As relações interpessoais também são contempladas ao se trabalhar com a Espiritualidade, que prima pela concepção de um Ser Humano Integral e que capacita o sujeito a produzir relações interpessoais mais fluidas e assertivas, cuidando da ética e do respeito/cuidado ao Outro, na medida em que encontra propósito e significado para sua vida (LOUSADA, 2017; GODOY, 2011).

Esta investigação também parece indicar que muitos são os sujeitos que precisam de um processo de compreensão intrapsíquica, pois, desde a educação infantil até a educação superior, professores e profissionais de áreas diversas estão sendo convidados a pensar, refletir e incluir o autoconhecimento em suas práticas. No caso de professores, diferente de outros profissionais, a necessidade é que

\footnotetext{
${ }^{1}$ Um mergulho em si mesmo, individual, afetivo, experiencial, autônomo; um desenvolvimento interior sem interferência externa. Como promotora de contato com a criatividade, valores, visão ecológica e com os sentimentos de liberdade, fé e autenticidade. O fenômeno da espiritualidade permite uma interpretação de sentido pela pessoa que a define, mostrando-se como um conceito amplo e com potencial comunicativo, sendo encontrado em todas as culturas e todas as idades (LOUSADA, 2017, p. 163)

2 [...] uma atividade livre e não religiosa (LOUSADA, 2017, p.181-182)
} 
promovam o autoconhecimento de si, pois precisarão ensinar e instigar/impulsionar seus alunos (o Outro) neste "mergulho" ao encontro de si mesmo, o que torna a atividade de autoconhecer-se merecedora de atenção, ética e profissionalismo.

O que se apresenta como tarefa da Educação, neste contexto, é abarcar este desenvolvimento, visto que a necessidade da competência do autoconhecimento e do autocuidado se mostra cada vez mais premente no planeta e a "escola/curso/universidade" é o lócus mais específico para auxiliar quanto a tal incumbência.

Trabalhar com a espiritualidade e com uma visão holística pressupõe, por sua vez, trabalhar com as dimensões físico/corporal, afetivo/emocional, cognitivo/mental, social e espiritual/transcendente, isto é, com o Ser Humano na sua integralidade. Ainda há muito a ser feito e desenvolvido até que possamos cuidar de nossa espécie como um Ser Humano Integral e conseguir contemplar todos os seus aspectos, e este artigo se destina a colaborar nesta direção.

\section{Referências}

ALMEIDA, L. R. Diário de itinerância, recurso para formação e avaliação de estudantes universitários. Estudos em Avaliação Educacional, v. 23, n. 51, p. 250-269, 2012. https://doi.org/10.18222/eae235120121961

ANDRADE, S. M. A. C. O autoconhecimento e autocuidado na formação interdisciplinar do profissional da saúde: uma jornada simbólica. Orientadora: Ivani Catarina Arantes Fazenda. 2018. 244 f. Tese (Doutorado em Educação: Currículo) - Programa de Estudos Pós-Graduados em Educação: Currículo, Pontifícia Universidade Católica de São Paulo, São Paulo, 2018. Disponível em: https://tede2.pucsp.br/handle/handle/21550. Acessado em: 24 ago. 2020.

ANTUNES, D. D.; PLASZEWSKI, H. O ser professor em contínua construção. Educação, Porto Alegre, v. 41, n. 1, p. 30-40, 2018. http://dx.doi.org/10.15448/19812582.2018.1.29782.

BASEI, A. P.; BENDRATH, E. A. Habitus e habitus de classe: analogias com o desenvolvimento profissional dos professores de educação física. Acta Scientiarum. Education, v. 38, n. 3, p. 319-327, 2016. Disponível em: http://dx.doi.org/10.4025/actascieduc.v38i3.27996.

BRASIL. Ministério da Educação. Base Nacional Comum Curricular. Brasília: MEC/SEB, 2017. Disponível em:

http://basenacionalcomum.mec.gov.br/images/BNCC_EI_EF_110518_versaofinal_site.p df. Acesso em: 14 ago. 2020.

BRASIL. Ministério da Educação. Resolução define diretrizes para formação de professores. Brasília: MEC/SEB. Atualização em 17 abr. 2020. Disponível em https://www.gov.br/mec/pt- 
br/assuntos/noticias/resolucao-define-diretrizes-para-formacao-de-professores: Acessado em 14 de agosto de 2020.

CORREA, A. C. E. Do vivido ontem ao realizado hoje: marcas que reverberam na ação docente. Orientadora: Laurinda Ramalho de Almeida. 2020. 163 f. Dissertação (Mestrado em Educação: Formação de Formadores) - Programa de Estudos Pós-Graduados em Educação: Formação de Formadores, Pontifícia Universidade Católica de São Paulo, São Paulo, 2020. Disponível em: https://tede2.pucsp.br/handle/handle/23149. Acesso em: 24 ago. 2020.

CORREA, G. C. P. Teia Multicultural: a construção de um modelo inovador na escola brasileira. Orientadora: Ivani Catarina Arantes Fazenda. 2018. 195 f. Dissertação (Mestrado em Educação: Currículo) - Programa de Estudos Pós-Graduados em Educação: Currículo, Pontifícia Universidade Católica de São Paulo, São Paulo, 2018. Disponível em: https://tede2.pucsp.br/handle/handle/21702. Acesso em: 24 ago. 2020.

CUNHA, R. C. O. B.; PRADO, G. V. T. Formação centrada na escola, desenvolvimento pessoal e profissional de professores. Educ. Puc. [online], n. 28, p. 101-111, 2010. Disponível em: http://educa.fcc.org.br/pdf/edpuc/n28/n28a10.pdf. Acesso em: 18 ago. 2020.

DANTAS, P. F. R. A prática reflexiva na formação continuada de docentes e suas implicações para o processo de inclusão escolar. Orientadora: Rita de Cássia Barbosa Paiva Magalhães. 2016. 331f. Tese (Doutorado em Educação) - Centro de Educação, Universidade Federal do Rio Grande do Norte, Natal, 2016.2 Disponível em: https://repositorio.ufrn.br/jspui/handle/123456789/22529. Acesso em: 24 ago. 2020.

DOMINGUES, C. As significações de professores readaptados sobre as condições de trabalho docente e suas implicações no processo de adoecimento. Orientadora: Wanda Maria Junqueira de Aguiar. 2018. 141 f. Dissertação (Mestrado em Educação: Formação de Formadores) — Programa de Estudos Pós-Graduados em Educação: Formação de Formadores, Pontifícia Universidade Católica de São Paulo, São Paulo, 2018. Disponível em: https://tede2.pucsp.br/handle/handle/21685. Acessado em: 24/08/2020.

FERNANDES, P. J. C. De educador a administrador; de administrador a educador: uma narrativa interdisciplinar como possibilidade de currículo para o educador administrador escolar contemporâneo. Orientadora: Ivani Catarina Arantes Fazenda. 2018. 129 f. Tese (Doutorado em Educação: Currículo) - Programa de Estudos Pós-Graduados em Educação: Currículo, Pontifícia Universidade Católica de São Paulo, São Paulo, 2018. Disponível em: https://tede2.pucsp.br/handle/handle/21437. Acessado em: 24/08/2020.

GODOY, H. P. A consciência espiritual na educação interdisciplinar. Orientadora: Ivani Catarina Arantes Fazenda. 2011. 113 f. Tese (Doutorado em educação) - Pontifícia Universidade Católica de São Paulo, São Paulo, 2011.

LOUSADA, M. G. A Espiritualidade na obra de autores da Psicologia, Saúde e Educação. Orientadora: Clarilza Prado de Sousa. 2017. Tese (Psicologia da Educação) - Pontifícia Universidade Católica de São Paulo, São Paulo, 2017.

MIGNOT, A. C. V. Exercício de intimidade: uma aproximação com a aprendizagem da escrita de si. Educação e Contemporaneidade: Revista da FAAEBA, v. 22, n. 40, p. 237-246, 2013. Disponível em: http://educa.fcc.org.br/pdf/faeeba/v22n40/v22n40a21.pdf. Acesso em: 18 ago. 2020. 
NOVAIS, L. E. D. Escola na contemporaneidade e o sentido bumaniz̧ador da educação: concepções da Igreja Católica Apostólica Romana. Orientadora: Nadia Dumara Ruiz Silveira. 2016. 103 f. Dissertação (Mestrado em Educação: Currículo) — Programa de Estudos Pós-Graduados em Educação: Currículo, Pontifícia Universidade Católica de São Paulo, São Paulo, 2016. Disponível em: https://tede2.pucsp.br/handle/handle/19629. Acesso em: 24 ago. 2020.

PEREIRA, L. H. P.; LIMA, C. L. Bioexpressão: uma proposta de formação integral dos alunos do curso de Pedagogia. Série-Estudos, Campo Grande, n. 36, p. 189-205, 2013. Disponível em: https://www.serie-estudos.ucdb.br/serie-estudos/article/view/706. Acesso em: 24 ago. 2020.

REIS, R. A. O olhar de um dirigente educacional municipal frente à formação continuada de professores com uma abordagem interdisciplinar. Orientador: Fernando José de Almeida. 2019. 148 f. Tese (Doutorado em Educação: Currículo) - Programa de Estudos Pós-Graduados em Educação: Currículo, Pontifícia Universidade Católica de São Paulo, São Paulo, 2019. Disponível em: https://tede2.pucsp.br/handle/handle/22477. Acesso em: 24 ago. 2020.

ROSA, G. F. C.; ROSA, M. H.; BARROS, M. C. V.; HATTORI, W. T.; PAULINO, D. B.; RAIMONDI, G. A. O MBTI na Educação Médica: uma Estratégia Potente para Aprimorar o Trabalho em Equipe. Revista Brasileira de Educaşão Médica, v. 43, n. 4, p. 15-25, 2019. http://dx.doi.org/10.1590/1981-52712015v43n4rb20180265.

SANTOS, A. C. D. GASPARIM, C. A.; MONTEIRO, G. M.; BRITO, M. R.; SILVA, V. A. M. da. Relato de Experiência: Construção e Desenvolvimento do Programa de Saúde na Escola (PSE) sob a Perspectiva da Sexualidade na Adolescência. Revista Brasileira de Educação Médica, v. 43, n. 4, p. 193-199, 2019. http://dx.doi.org/10.1590/1981$52712015 \mathrm{v} 43 \mathrm{n} 4 \mathrm{rb} 20180248$.

SANTOS, B. S.; ANTUNES, D. D.; BERNARDI, J. O docente e sua subjetividade nos processos motivacionais. Educação, Porto Alegre, v. 31, n. 1, p. 46-53, 2008. Disponível em: https://revistaseletronicas.pucrs.br/ojs/index.php/faced/article/view/2757. Acesso em: 18 ago. 2020.

SANTOS, L. H. Educação Sexual no Ensino Fundamental: construindo uma unidade didática. Orientadora: Francele de Abreu Carlan. 2019. 149 f. Dissertação (Mestrado em Ensino de Ciências e Matemática) - Programa de Pós-Graduação em Ensino de Ciências e Matemática, Faculdade de Educação, Universidade Federal de Pelotas, Pelotas, 2019. Disponível em: http://guaiaca.ufpel.edu.br:8080/handle/prefix/4901. Acesso em: 24 ago. 2020.

SCHEFFER, A. M. M. O cronotopo sala de leitura e a formação do leitor literário. Orientadora: Hilda Aparecida Linhares da Silva Micarello. 2019. 239 p. Tese (Doutorado em Educação) Programa de Pós-graduação em Educação, Universidade Federal de Juiz de Fora, Juiz de Fora, 2019.

SILVEIRA, C. S. A escola como lócus de formação: uma proposta de desenvolvimento profissional docente. Orientador: Verno Krüger. 2017. 138f. Dissertação (Mestrado em Ensino de Ciências) - Universidade Federal de Pelotas, Pelotas, 2017. Disponível em: http://guaiaca.ufpel.edu.br:8080/handle/prefix/3781. Acessado em: 24 ago. 2020.

SOARES, L. C. F.; MENEZES, C. M. A.; FREIRE, J. L. O. As histórias de vida na profissão docente: uma contribuição para a história da educação, itinerâncias formativas e $\mathrm{O}$ 
autoconhecimento. Educ. Teoria Prática, v. 26, n. 53, p. 428-444, 2016. https://doi.org/10.18675/1981-8106.vol26.n53.p428-444.

UNIVERSIDADE FEDERAL RURAL DA AMAZÔNIA. Biblioteca Maria Auxiliadora Feio Gomes. Perguntas frequentes. 2019. Disponível em: https:/ / bibliotecacp.ufra.edu.br/index.php?option=com_content\&view=article\&id=28\&It emid=131. Acesso em: 25 ago. 2021.

WEBER, J. F. Singularidade e formação (Bildung) em Schopenhauer como educador de Nietzsche. Educ. Pesqui., v. 35, n. 2, p. 251-264, 2009. https://doi.org/10.1590/S151797022009000200003.

RECEBIDO: 21/04/2021

APROVADO: 20/07/2021
RECEIVED: 04/21/2021

APPROVED: 07/20/2021
RECIBIDO: 21/04/2021

APROBADO: 20/07/2021 